\title{
10 health stories that mattered: Mar. 10-14
}

- As Quebec's provincial election looms on Apr. 7, the province's Conservative Party leader is advocating for more private sector involvement in health care. Adrien Pouliot says physicians should be allowed to charge for services outside the public system, with patients paying out-of-pocket then seeking reimbursement from the government. Pouliot says the Quebec system, which has such problems as lack of access to family doctors and long wait times, "does not meet the expectations of Quebecers and is in a financial bind." Meanwhile, the Quebec Liberal Party says it will invest $\$ 400$ million over five years to hire more medical professionals and improve access to health care.

- The federal auditor has delivered a scathing assessment of the Northwest Territories' child fostering system. The Office of the Auditor General of Canada found that foster parents were not screened in $69 \%$ of the cases reviewed and that half of the plans of care weren't monitored. It also found that $28 \%$ of reports of children at risk were never investigated. About 1000 children receive care in the territory every year; $95 \%$ of them are Aboriginal.

- Canada spent a record-breaking \$29.3 billion on prescription drugs in 2013, although the rate of spending has slowed with the growing number of generic drugs due to expiring patents. The Canadian Institute for Health Information reports that spending last year increased $2.3 \%$, the second lowest rate in a decade (the lowest was $1.3 \%$ in 2011). Prescribed drugs accounted for an estimated $13.9 \%$ of total health care expenditures in 2013.
- Palliative care will receive $\$ 3$ million over three years from the federal government for training and education. The funding, which goes to the Pallium Foundation of Canada, was promised a year ago in the 2013 federal budget. Fewer than one-third of Canadians now have access to palliative care, according to the Canadian Institute for Health Information.

- The College of Family Physicians of Canada welcomed the opportunity to take part in a federal government round table on preventing family violence and child maltreatment. College President, Dr. Kathy Lawrence, said in a media release that she was "encouraged" to hear Health Minister Rona Ambrose "willing to fund a secretariat to assist in educating physicians and other health professionals in addressing family violence with a focus on child maltreatment."

- Ontario hospitals that implemented a World Health Organizationdesigned safe surgery checklist saw no measurable improvement in operative mortality or complications, finds a new study in the New England Journal of Medicine. The study involved 101 Ontario hospitals during three-month periods both before and after adoption of the checklist.

- A farmer who is fighting for his right to sell unpasteurized milk has vowed to take his case to the Supreme Court of Canada. Michael Schmidt who farms in the Municipality of West Gray in Southwestern Ontario, was convicted and fined $\$ 9150$ under provincial healthprotection laws in 2011. Schmidt lost his Ontario Court of Appeal case Mar. 13.

- Manitoba's government is opening 14 health centres with a view to fulfilling its 2011 election promise to provide a family doctor for every resident by 2015. About $15 \%$ of Manitobans currently lack a doctor. The new centres, called My Health Teams, will include doctors, nurses, nurse practitioners, midwives, dietitians, pharmacists and other health professionals.

- Health Canada is spending $\$ 133000$ to study retail sales of electronic cigarettes and nonpharmaceutical nicotine replacement therapy products from 2012/13 through 2014/15, according to a report in The Chronicle Herald in Halifax, Nova Scotia. Health Canada does not allow the sale of e-cigarettes containing nicotine. Health Minister Rona Ambrose isn't saying if the research could be used to craft new legislation.

- Nearly 100 patients in Gander, Newfoundland and Labrador are being retested for pulmonary function after routine quality assurance checks revealed that the equipment used to calibrate diagnostic machines had malfunctioned. In addition, investigators found that the reports of 34 patients were not reviewed by an appropriate physician, while the status of 18 other reports is unknown. The tests in question were performed between Jan. 13 and Feb. 19. Central Health, which is investigating, says it is too early to know whether the issues have had an effect on patients' health. - Barbara Sibbald, CMAJ

CMAJ 2014. DOI:10.1503/cmaj.109-4760 